\title{
SCREENING DE ATIVIDADE CITOTÓXICA DE EXTRATOS LIQUÊNICOS: CLADONIACEAE
}

\author{
Silene C. Nascimento ${ }^{1}$ \\ Eugênia C. Pereira ${ }^{2.3}$ \\ Antonio Fernando M. Oliveira ${ }^{2}$ \\ Nicácio Henrique da Silva ${ }^{4}$ \\ Michele Boitard ${ }^{5}$ \\ Hélène Beriel ${ }^{5}$
}

Recebido em 16.09.91. Aceito em 11.07.94

\begin{abstract}
RESUMO - (Screening de atividade citotóxica de extratos liquênicos: Cladoniaceae) Extratos etéreos, acetônicos, metanólicos e aquosos de Cladonia substellata, C. crispatula e Cladina dendroides ocorrentes em solos arenosos de tabuleiros (cerrado) no Estado da Paraíba (Brasil), foram testados contra células PC3 e MDA-MB231 obtidas de adenocarcinoma prostático e mamário (humanos), bem como células P388 e L1210 provinientes de leucemia murina. Os resultados demonstraram uma maior eficácia dos extratos de $C$. substellata frente às quatro células testadas. Esta espécie e a Cladina dendroides, exceto seu extrato metanólico, apresentaram $\mathrm{IC}_{50}$ inferiores a $50 \mu \mathrm{g} / \mathrm{ml}$, o que indica atividade satisfatória. Os extratos de C. crispatula não exerceram inibição relevante frente às células estudadas. Testes cromatográficos revelaram, em maior quantidade, a presença dos ácidos úsnico e estítico em C. substellata; ácido tamnólico em C. crispatula; atranorina e os ácidos protocetrárico e fumarprotocetrárico em $C$. dendroides, o que se supõe ser o princípio ativo dessas espécies.
\end{abstract}

Palavras-chave: atividade citotóxica, líquen, Cladoniaceae.

\begin{abstract}
Screening of cytotoxic activity of lichen crude extracts:Cladoniaceae) Ethereous, acetonic and methanolic crude extracts from Cladonia substellata, C. Crispatula and Cladina dendroides occured on sandy soil of Paraiba State - Brazil, were tested against PC3 and MDAMB231 cells from prostatic and breast human adenocarcinom, and P388 and L1210 cells from murine leukemia. The results showed the highest inhibition of Cladonia substellata extracts against the four tested cells. This specie and Cladina dendroides, except its methanolic extract, presented $\mathrm{IC}_{50}$ lower than $50 \mu \mathrm{g} / \mathrm{ml}$ that indicates a satisfactory activity. Cladonia crispatula extracts did not
\end{abstract}

\footnotetext{
Departamentos de Antibióticos ', Botânica 2, Bioquímica ${ }^{4}$, Centro de Ciências Biológicas, Universidade Federal de Pernambuco, Av. Prof. Nelson Chaves,s/n, 50.739, Cidade Universitária, Recife - PE, Brasil. Laboratório de Farmacologia e Fisiologia ${ }^{5}$, U.F.R. Farmácia, Université Joseph Fourier, 38.000 La Tronche, França.
} 
exert inhibition on the studied cells. Chromatographic tests revealed the presence, in highest content, of usnic an stictic acids in C. substellata; thamnolic acid in C. crispatula protocetraric and fumarprocetraric acids and atranorin in $C$. dendroides, what one may suppose to be the active principles of the studied species.

Key words: activity cytotoxic, lichen, Cladoniaceae.

\section{Introdução}

Os líquens, seres simbiontes compostos de alga e fungo, produzem metabólitos secundários de comprovada atividade biológica.

As substâncias liquênicas são eficientes contra bactérias e fungos (Bustinza 1951, Pereira 1989, Pereira et al. 1991), impedem o desenvolvimento de tumores e células cancerígenas (Fukuoka et al. 1968, Lima et al. 1990, Pereira et al. no prelo), além de possuirem atividade farmacológica (Appa-Rao \& Prabhakar 1987, Correia da Silva 1979), antigerminativa (Ravinskaya \& Vainhstein 1975, Lawrey 1977), dentre outras.

As culturas de células humanas e animais são essenciais aos estudos in vitro de atividade citotóxica de substâncias sintéticas ou naturais. Esses testes, incorporados ao programa do National Cancer Institute, objetivam a pré-seleção de agentes antitumorais. O estudo de atividade citotóxica permite estabelecer correlação entre os resultados obtidos in vitro e in vivo, fornecendo informações suplementares aos estudos das neoplasias.

Com base na bibliografia que refere a atividade antitumoral dos polissacarídeos e fenóis liquênicos obtidos de diferentes espécies de líquens, foram iniciados estudos por Lima et al.(1990), com extratos de Cladoniaceae ocorrentes em tabuleiros arenosos do Estado da Paraíba, Brasil. Os resultados demonstraram que espécies com alto teor de ácido úsnico inibiram, in vitro, o crescimento de células da linha contínua KB (carcinoma nasofaríngeo), bem como impediram o desenvolvimento de tumores sólidos experimentais do tipo sarcoma-180 e carcinoma de Ehrlich, em até $80 \%$.

Neste trabalho foi realizado o estudo da atividade citotóxica de extratos de Cladonia substellata Vainio, Cladonia crispatula(Nyl.) Ahti e Cladina dendroides (des Abb.) Ahti, contra quatro diferentes tipos de células, como continuidade da investigação de compostos liquênicos com atividade antineoplásica.

\section{Material e métodos}

\section{Coleta do líquen e preparo dos extratos}

Para este trabalho foram selecionadas Cladonia substellata Vainio, Cladonia crispatula (Nyl.) Ahti, e Cladina dendroides (des Abb.) Ahti, ocorrentes sobre solos arenosos de tabuleiros (cerrado), no Estado da Paraíba, Brasil.

Utilizando-se $10 \mathrm{~g}$ de talo seco e solventes orgânicos, em série eluotrópica (éter, acetona e metanol), foram obtidos extratos, por sistema de esgotamento a frio, em agitador mecânico por $1 \mathrm{~h}$ à temperatura ambiente (cerca de $28^{\circ} \mathrm{C}$ ). Do resíduo, se realizou extração aquosa a frio e a quente, esta última a $100^{\circ} \mathrm{C}$ por $1 \mathrm{~h}$. 
Os extratos orgânicos foram evaporados à temperatura ambiente, enquanto os aquosos foram congelados e liofilizados.

\section{Cromatografia em camada delgada}

Os extratos orgânicos foram aplicados em placas de $20 \times 20 \mathrm{~cm}$, com $0,25 \mathrm{~mm}$ de sílica Gel60 $\mathrm{F}_{254+366}$ Merck, desenvolvidas nos sistemas de solventes A (tolueno/ dioxano/ácido acético, 180:45:5 v/v) e B (hexano/éter dietílico/ácido fórmico, 130:80:20 v/v), segundo Culberson (1972).

As bandas isoladas foram reveladas e demarcadas sob luz UV a 254 e 366nm. Em seguida, as placas foram pulverizadas com $\mathrm{H}_{2} \mathrm{SO}_{4}$ a $10 \%$, e levadas à estufa a $100^{\circ} \mathrm{C}$ por $1 \mathrm{~h}$.

Os cromatogramas foram interpretados com base nos valores de $\mathrm{Rf}$ das bandas e padrões utilizados (ácido fumarprotocetrárico, protocetrárico, tamnólico, decarboxitamnólico, estítico e úsnico, além da atranorina), bem como pela coloração resultante da reação das bandas com o ácido sulfúrico.

\section{Testes in vitro}

Nos testes de citotoxidade foram utilizadas quatro linhas contínuas de células. As linhas humanas (Furlay \& Baguley 1984) PC $_{3}$ e MDA-MB231 foram obtidas de adenocarcinoma prostático e mamário, respectivamente (Kaighn et al. 1979, Cailleau et al.,1974), enquanto as P388 e L1210 eram provinientes de leucemia murina (De Bruyn 1955; Hutchison et al. 1966; Moore et al. 1966; Baguley \& Nash 1981).

As células PC3 foram cultivadas em uma mistura contendo $25 \%$ do meio Eagle modificado (MEM - Modified Eagle Medium), 65\% do meio F12 (Nutried Mixture), HAM Gibco enriquecido com $10 \%$ de soro fetal bovino, $2 \mu \mathrm{M} / \mathrm{ml}$ de L-glutamina e antibióticos (penicilina - $1000 \mathrm{UI} / \mathrm{ml}$; estreptomicina - 250 $\mu \mathrm{g} / \mathrm{ml}$; anfotericina - 2,5 $\mu \mathrm{g}$ / $\mathrm{ml}$ ); as MDA-MB231 foram cultivadas no meio Eagle modificados com $10 \%$ de soro fetal bovino, $2 \mu \mathrm{M} / \mathrm{ml}$ de L-glutamina, antibióticos (penicilina - $1000 \mathrm{UI} / \mathrm{ml}$ e estreptomicina - $250 \mu \mathrm{g} / \mathrm{ml}$ ) e $1 \mathrm{UI} / \mathrm{ml}$ de insulina; as células $\mathrm{L}_{1210}$ e $\mathrm{P}_{388}$ foram cultivadas no RPMI(Roswell Park Memorial Institute)com 10\% de soro fetal bovino, $2 \mu \mathrm{M} / \mathrm{ml}$ de L-glutamina, $10 \mu \mathrm{g} / \mathrm{ml}$ de 2 -mercaptoetanol e antibióticos (penicilina - $1000 \mathrm{UI} / \mathrm{ml}$; estreptomicina - $250 \mu \mathrm{g} / \mathrm{ml}$ ).

Para todas as linhas celulares a viabilidade foi determinada pelo teste de exclusão do azul de tripano, e a suspensão celular ajustada para $10^{4}$ células $/ \mathrm{ml}$.

As suspensões celulares foram divididas em placas multipontos a uma razão de $135 \mu \mathrm{l}$ para as linhas MDA-MB231 e PC3, e 250 $\mu$ l no caso das L1210 e P388.

Os extratos liquênicos foram solubilizados pelo di-metil sulfóxido (MDSO), e colocados em três pontos por concentração para as linhas L1210 e P388, e quatro pontos para as MDA-MB231 e PC3. A média dos pontos por concentração foi feita com objetivo de calcular a percentagem de inibição do crescimento das células tratadas em relação ao grupo controle.

As células das linhas L1210 e P388 foram contadas pelo Coulter Counter (Modelo TA Contronic - France). O desenvolvimento das células tratadas foi compa- 
rado ao das células controle, onde a percentagem de inibição foi calculada através da fórmula: (C - T) / C x 100, onde C é a média das células controle, e T é a média das células tratadas.

Para as linhas PC3 e MDA-MB231, a avalilação foi feita pelo método colorimétrico do MTT,(3-4 dimethiltiazol - 2 y1 2,5 diphenyltetrazolium bromide), segundo COLE (1986). Após cinco dias de incubação das células com os extratos liquênicos, foram adicionados $15 \mu \mathrm{l}$ da solução de MTT $(5 \mathrm{mg} / \mathrm{ml}$ PBS $)$, e as placas recolocadas na estufa. Após $2 \mathrm{~h}$, a reação enzimática foi interrompida por aspiração do meio de cultura, e adição de $100 \mu \mathrm{l}$ de DMSO. As placas foram agitadas por 10min e a leitura espectrocolorimétrica dos cristais formados foi realizada a um comprimento de onda de 540nm, através do Titerk Multiscan (Flow), acoplado a um computador Macintosh Plus.

\section{Resultados e discussão}

Os testes cromatográficos (Figura 1) revelaram a presença do ácido úsnico nos extratos etéreo, acetônico e metanólico de Cladonia substellata. Foi detectada uma banda no extrato etéreo de Rf semelhante ao do ácido estítico padrão. As outras bandas não identificadas, podem ser dos ácidos constítico e criptoestítico, além de um diterpeno. Ahti (1973) constata a presença dessas substâncias em C. substellata e refere o ácido úsnico como seu principal componente $(98,1 \%)$. Estes dados foram confirmados por Pereira et al.(1991).

Cladonia crispatula, antes confundida com C. gorgonia, notadamente as espécies coletadas no Brasil, tem como principal componente o ácido tamnólico (Ahti, 1977). Pereira (1989) também detectou a presença deste ácido, além de quatro frações não identificadas, uma delas provavelmente o ácido decarboxitamnólico. Os dados obtidos por Pereira (1989) são ratificados nos testes cromatográficos aqui realizados (Figura 1 ).

Ainda na Figura 1, pode ser observado o desenvolvimento dos extratos de Cladina dendroides. Huovinen \& Ahti (1986) atribuem para esta espécie a atranorina como principal componente, assim como a presença dos ácidos protocetrárico e fumarprotocetrárico, além da substância $\mathrm{CPh}_{2}$. Por outro lado, Legaz et al.(1987) referem a presença do ácido úsnico em $C$. dendroides. Estes dados foram confirmados por Pereira (1989), entretanto nos testes aqui realizados, este composto não foi detectado.

Em relação à atividade citotóxica, Cladonia substellata foi a espécie cujos extratos exerceram maior poder inibidor frente às células testadas. Na Tabela 1 é possível observar a $\mathrm{IC}_{50}$ * dos extratos testados. Quando o extrato bruto tem $\mathrm{IC}_{50}$ menor que $50 \mu \mathrm{g} / \mathrm{ml}$, o resultado é considerado satisfatório para o prosseguimento nos estudos antineoplásicos. Portanto, quanto menor a concentração da substância para

* Concentração que inibe $50 \%$ do crescimento celular. 
SISTEMA A

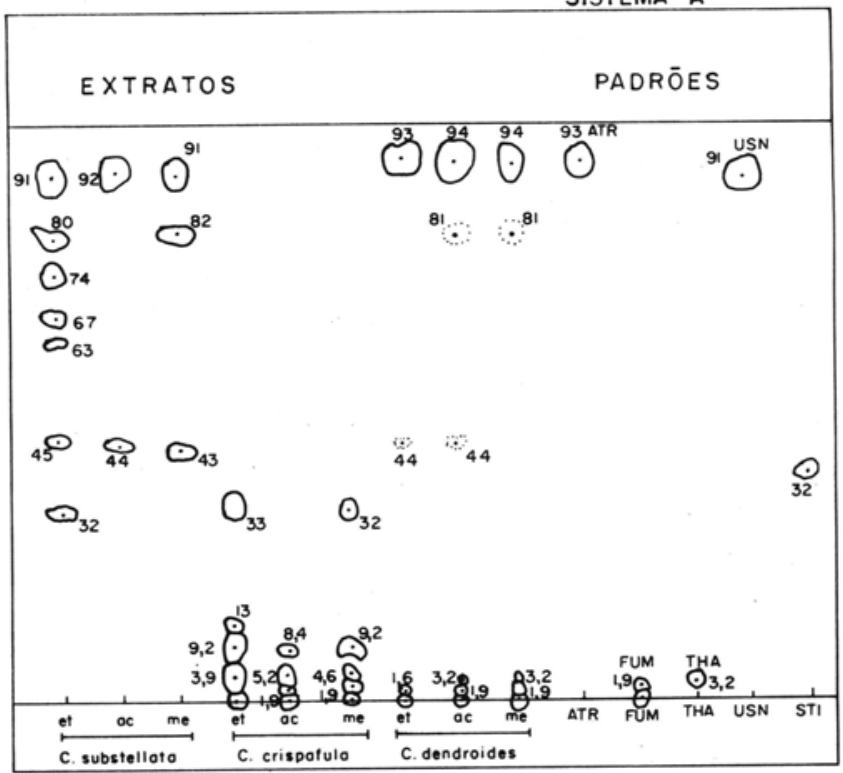

SISTEMA B

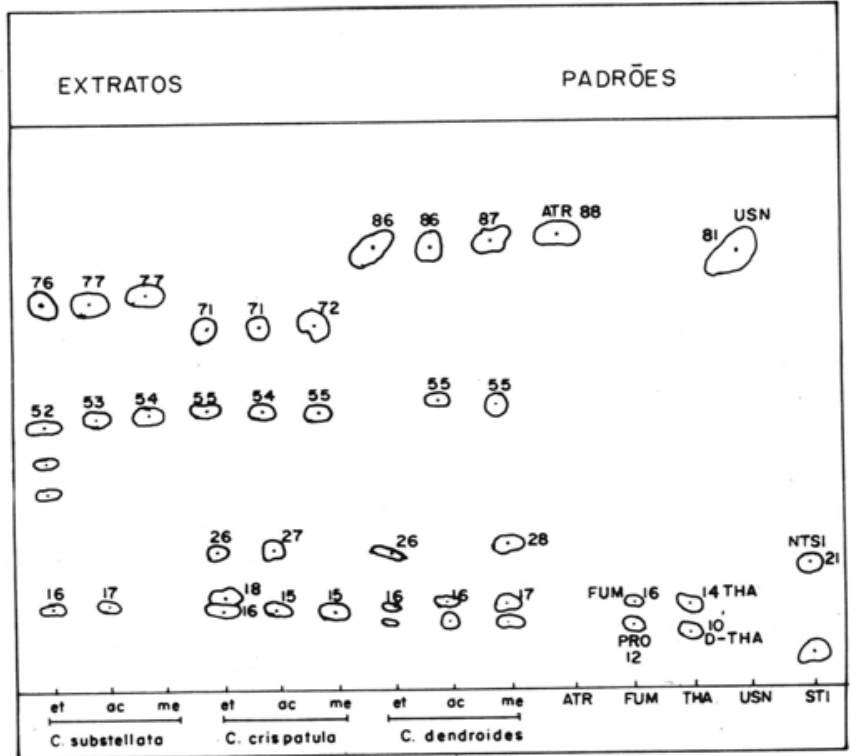

Figura 1. Cromatograma dos extratos etéreos, acetônicos e metanólicos obtidos de Cladonia substellata, C. crispatula e Cladina dendroides, desenvolvidos nos sistemas de solventes A (tolueno/dioxano/ácido acético, 180:45:5, v/v) e B (hexano/éter dietílico/ácido fórmico, 130:80:20, v/v). 
inibição de $50 \%$ do crescimento celular, provavelmente ela será menos tóxica ao organismo.

De acordo com a Tabela 1, pode-se observar que os extratos etéreo e metanólico de Cladonia crispatula, bem como o metanólico de Cladina dendroides tiveram $\mathrm{IC}_{50}$ maior que $50 \mu \mathrm{g} / \mathrm{ml}$, o que descarta esses extratos para estudos posteriores. Por outro lado, os extratos etéreo e acetônico de Cladina dendroides apresentaram $\mathrm{IC}_{50}$ bem inferiores contra as células PC3, L1210 e P388, e nenhum efeito frente às MDAMB231.

Os dados sobre C. substellata foram os mais interessantes dentre os obtidos, visto que seu extrato acetônico testado contra as células PC 3 apresentou $\mathrm{IC}_{50} \mathrm{de} 0,7 \mu \mathrm{g} /$ $\mathrm{ml}$, e para as leucêmicas L1210 e P388 uma inibição de $1,2 \mu \mathrm{g} / \mathrm{ml}$ e $1,3 \mu \mathrm{g} / \mathrm{ml}$, respectivamente. No que se refere a esta espécie, todos os seus extratos apresentaram inibição relevante, devendo ainda ser levado em consideração que está se trabalhando a nível de extrato bruto.

Os produtos de referência foram utilizados para verificar sensibilidade das células em estudo. Para as linhas L1210 e P388 foi utilizada a Adriamicina com $\mathrm{IC}_{50}$ de 0,054 e $0,018 \mu \mathrm{g} / \mathrm{ml}$, respectivamente, e Taxol com $\mathrm{IC}_{50}$ igual a $27 \mu \mathrm{g} / \mathrm{ml}$ para a linha $\mathrm{PC}_{3}$ e $30 \mu \mathrm{g} / \mathrm{ml}$ para as MDA-MB231.

Tabela 1: $\mathrm{IC}_{50} *(\mu \mathrm{g} / \mathrm{ml})$ de diferentes extratos celulares de Cladoniaceae sobre células cancerígenas

\begin{tabular}{llrrrr}
\hline $\begin{array}{l}\text { Linha Celular } \\
\text { Espécies }\end{array}$ & Extratos & PC3 & MDA/ & L1210 & P388 \\
\hline Cladonia & MB231 & & \\
substellata & etéreo & 10,4 & 19,8 & 6,8 & 5,9 \\
& acetônico & 0,7 & 18,3 & 1,2 & 1,3 \\
& metanólico & 6,7 & 5,9 & 4,9 & 3,7 \\
& aquosos & $>50$ & $>50$ & $>50$ & $>50$ \\
\hline \multirow{2}{*}{ cladonia } & etéreo & 50,0 & 50,0 & 50,0 & 50,0 \\
& acetônico & - & - & - & - \\
& metanólico & 50,0 & 50,0 & 50,0 & 50,0 \\
& aquosos & $>50$ & $>50$ & $>50$ & $>50$ \\
\hline \multirow{2}{*}{$\begin{array}{ll}\text { dendina } \\
\text { dendroides }\end{array}$} & etéreo & 16,8 & 50,0 & 11,1 & 8,3 \\
& acetônico & 15,9 & 50,0 & 13,9 & 13,5 \\
& metanólico & 50,0 & 50,0 & 50,0 & 50,0 \\
& aquosos & $>50$ & $>50$ & $>50$ & $>50$ \\
\hline
\end{tabular}

* Concentração que inibe $50 \%$ do crescimento celular. 
Quanto ao princípio ativo, o que se pode atribuir à inibição sempre mais acentuada do extrato acetônico, é o alto poder extrator da acetona.

Os líquens produzem metabólitos secundários alifáticos e fenólicos, na maioria extracelulares e insolúveis na água, sendo intracelulares as proteínas, carotenóides e vitaminas, estes encontrados na maioria das plantas superiores (Hale, 1983).

Os fenóis liquênicos, extraídos com solventes orgânicos, estão localizados na medula ou no córtex, raramente em ambas as camadas. As substâncias corticais são, na maioria, antraquinonas, derivados do ácido tetrônico, ácido úsnico, atranorina e liquexantona; os medulares são os depsídeos e depsidonas, não influindo, em ambos os casos, sua ocorrência e quantidade em relação à idade do talo liquênico (Hale, 1983; Xavier-Filho et al., 1985).

Segundo Vicente (comunicação pessoal) e Hale (1983), diferentes solventes extraem diferentes substâncias em distintas partes do talo, algumas localizadas a nível medular, outras no córtex. A acetona retira os fenóis totais (medulares e corticais), enquanto o metanol separa principalmente os corticais.

Face a estas considerações, pode-se concluir que o maior poder inibidor dos extratos acetônicos se deve à maior capacidade extratora da acetona, dentre os solventes utilizados.

Nas Figuras que seguem, é possível observar a percentagem de inibição do crescimento celular, bem como a relação dose-efeito. Estes dados dão uma idéia geral do comportamento dos extratos diante das linhas celulares estudadas.

Na Figura 2 é possível observar que as células PC3 podem ser inibidas acima de $85,1 \%, 89,2 \%$ e $87,2 \%$ pelos extratos etéreo, acetônico e metanólico de Cladonia substellata, na concentração de $50 \mu \mathrm{g} / \mathrm{ml}$; as células MDA-MB231 foram inibidas em $86,1 \%, 88,7 \%$ e $89,4 \%$ pelos mesmos extratos; as L1210 em 98,6\%, 98,2\% e 99,0\%, enquanto as P388 tiveram inibição de $98,7 \%, 98,6 \%$ e $99,2 \%$ na seqüência dos extratos supra referidos.

Tomando-se como base a concentração de $50 \mu \mathrm{g} / \mathrm{ml}$, não foi constatada inibição relevante dos extratos acetônico e metanólico de Cladonia crispatula, sendo registrada para o extrato acetônico a maior inibição, frente às células MDA-MB231 com $50,2 \%$ (Figura 3).

A mesma situação se repete para o extrato metanólico de Cladina dendroides na concentração de $50 \mu \mathrm{g} / \mathrm{ml}$ (Figura 4). Este inibiu em 53,3\% as células MDA-MB231, entretanto o extrato etéreo desta espécie, que inibiu fortemente as demais células testadas, só antagonizou em 39,5\% estas células. Isto torna possível supor que o princípio ativo deste extrato, é a atranorina, com provável associação ao complexo do ácido fumarprotocetrárico, detectados por CCD (Figura 1).

Ainda na Figura 4, pode-se atribuir para o extrato acetônico de $C$. dendroides a, $50 \mu \mathrm{g} / \mathrm{ml}$, uma inibição de $87,6 \%, 53,5 \%$ e 98,8\% frente às células PC3, MDAMB231, L1210 e P388; o extrato etéreo desta espécie inibiu as mesmas células em $86,4 \%, 39,5 \%, 96,5 \%$ e $98,2 \%$, respectivamente.

Os extratos aquosos das três espécies testadas não demonstraram atividade relevante, tendo sido detectado, em todos os casos, $\mathrm{IC}_{50}>50 \mu \mathrm{g} / \mathrm{ml}$. 


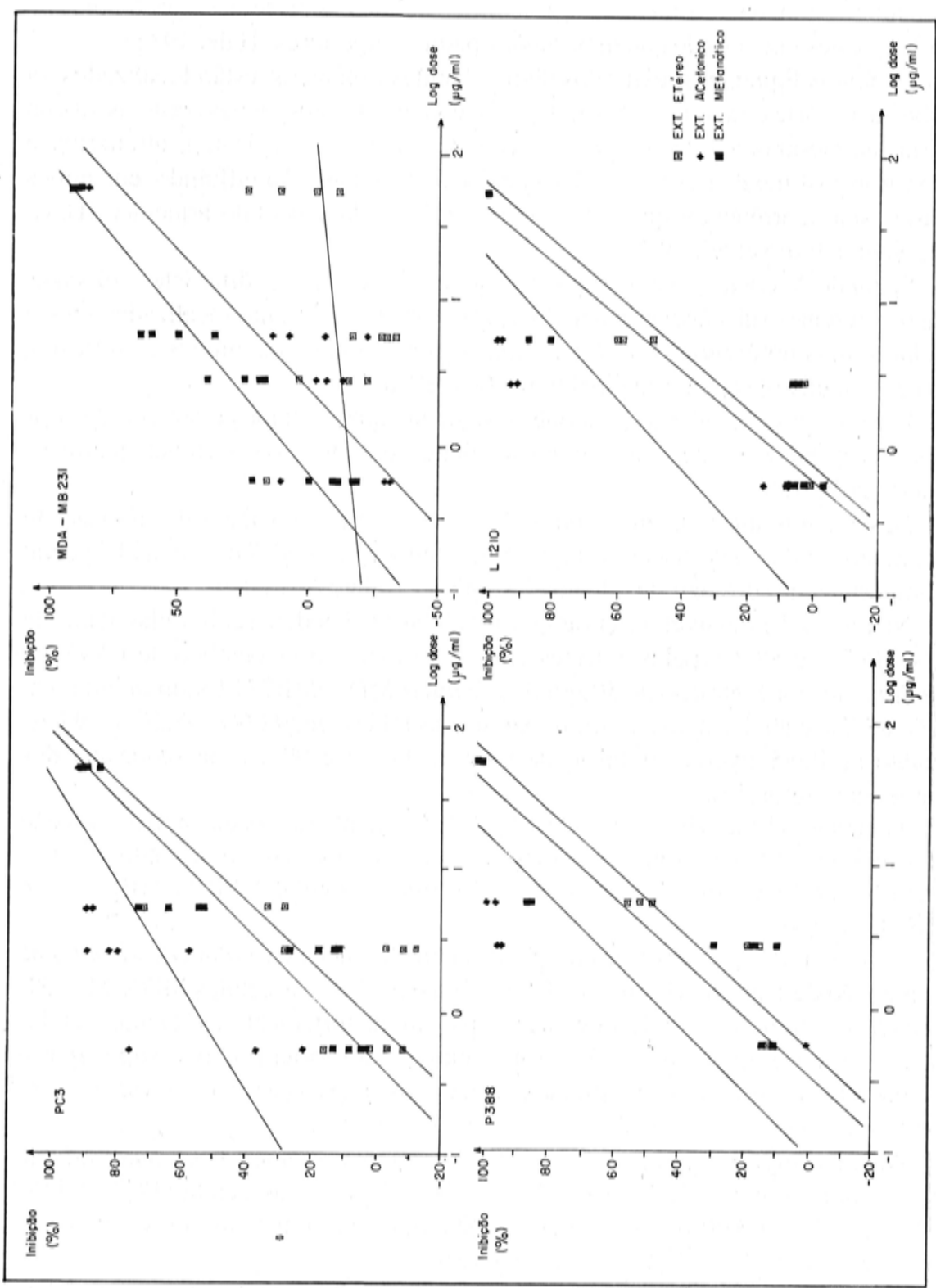




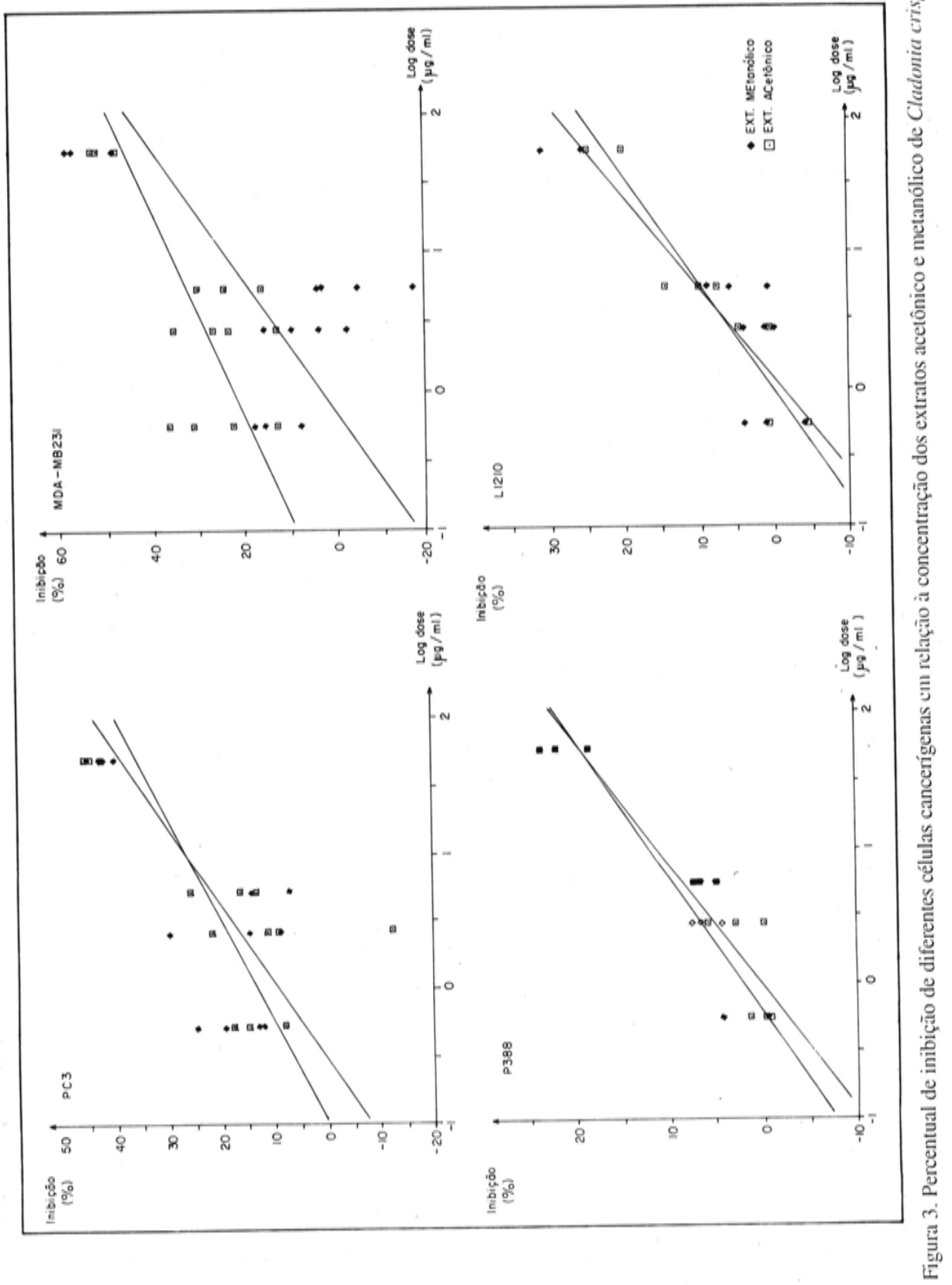




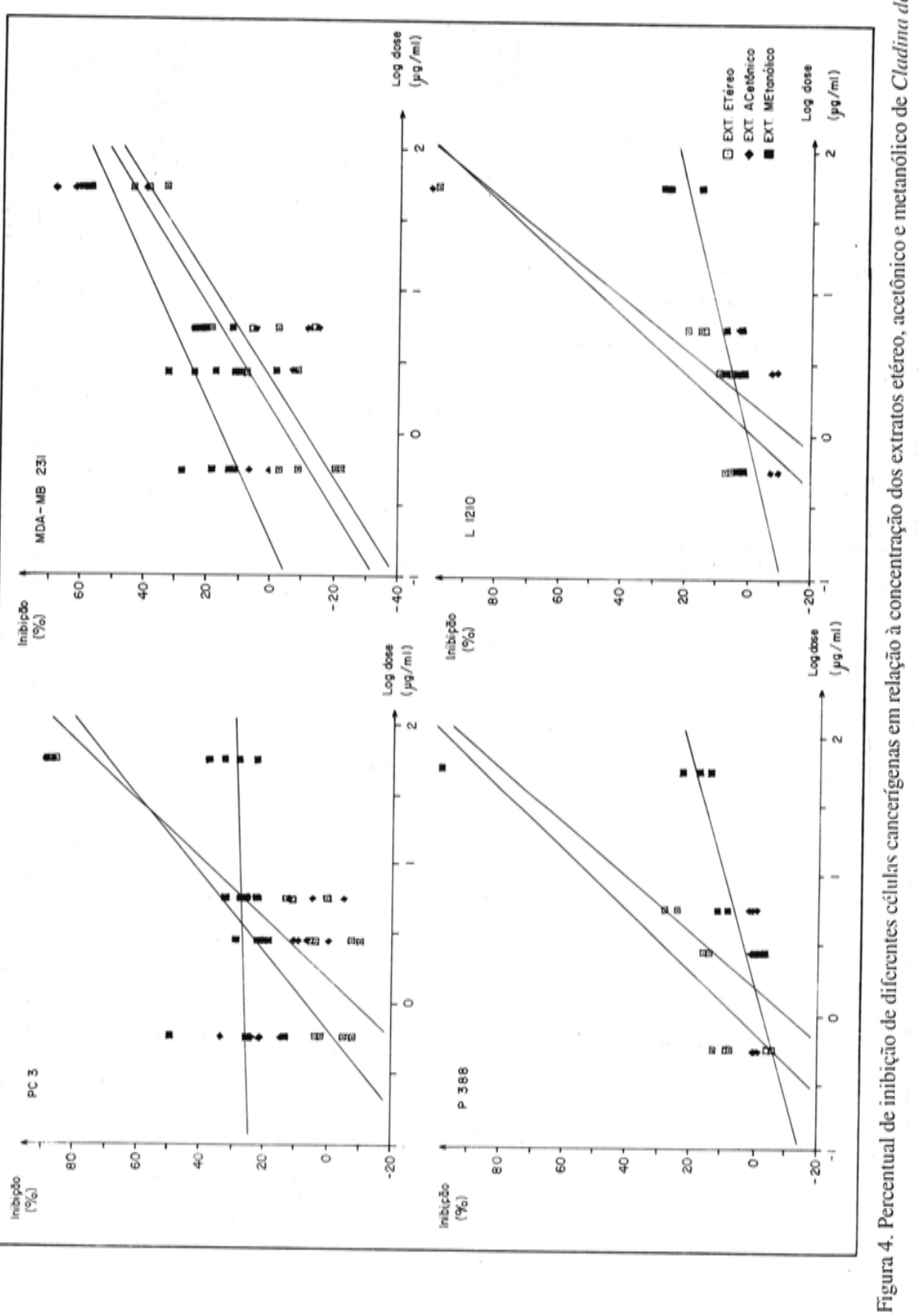


Face aos dados obtidos, foi possível concluir que, dentre as espécies testadas, Cladonia substellata foi a mais eficaz frente às quatro linhas celulares estudadas, e aos seus extratos sendo atribuído como princípio ativo o ácido úsnico, e um possível sinergismo com o ácido estítico; os extratos etéreo e acetônico foram os que extraíram maior quantidade de princípio ativo dos líquens, exceto no caso do extrato metanólico de Cladina dendroides contra as células MDA-MB231; os extratos acetônico e metanólico de Cladonia crispatula não demonstraram inibição relevante frente às células teste, daí deduzir-se a ineficiência do ácido tamnólico, principal composto da espécie, frente as linhas celulares testadas.

Que os princípios ativos das espécies de Cladoniaceae aqui estudadas são de natureza fenólica, visto a baixa eficácia dos extratos aquosos frente às células teste.

Estudos subseqüentes serão realizados com as substâncias aqui referidas como princípios ativos, já purificadas, para uma indicação mais precisa, e detecção dos possíveis efeitos sinérgicos.

\section{Agradecimentos}

Este trabalho contou com o apoio do CNPq (bolsista/IC) e FACEPE (APQ). Agradecemos ao Prof. Carlos Vicente Córdoba, da Universidad Complutense de Madrid, pela revisão do manuscrito.

\section{Referências bibliográficas}

Ahti, T. 1973. Taxonomic notes on some species of Cladonia subsect. Unciales. Ann. Bot. Fenn. 10:163184.

Ahti, T. 1977. The Cladonia gorgonia group and C. gigantea in East Africa. Lichenol. 9:1-15.

Appa-Rao, A. V. N. \& Prabhakar, M. C. 1987. Pharmacological actions of leprapinic acid, a lichen metabolite. Fitoterapia 58(4):221-228.

Baguley, B. C. \& Nash, R. 1981 Antitumor activity of substituted 9-aminoacridines. Comparison of in vivo and in vitro testing systems. Eur. J. Cancer 17:671-679.

Bustinza, F. 1951. Antibacterial substances from lichens. Endeavour 10(38):95-99.

Cailleau, R.; Yong, R., Olive, J., Reeves,W. 1974. Brest tumor cell lines from pleural effusion. J. Nat. Inst. 53:661-674.

Cole, S. P. C. 1986. Rapid chemosensivity testing of human lung tumor cell using MTT assay. Cancer Chemother. Pharmacol. 17:259-263.

Culberson, C. F. 1972. Improved conditions and new data for the identification of lichen products by standardized thin-layer chromatographic method. J. Chromatogr. 72:113-125.

Correia da Silva, J. 1979. Action of usnic acid on smooth muscle organs. Plant Med. Phytother. 13:26-33.

De Bruyn, W.M. 1955. The maintenance of leukemia cell and carcinoma cell in continuous culture in slightly modified erlenmayer flasks. Jaarb. Kankerondez Neder 5:137-142.

Fukuoka, F., Nakanishi, M., Shibata, S., Nishikawa, Y., Takeda, T.; Tanaka, M. 1968. Polysaccharides in lichens and fungi II. Antitumor activities on sarcoma-180 of the polysaccharide preparations from $G$. esculenta, C. islandica, and some other lichens. Gann. 59:421-432.

Furlay, G. J. \& Baguley, B. C. 1984. The use of human cancer cell lines as a primary screening system for antineoplasic compounds. Eur. J. Cancer Clin. Oncol. 20:947-954.

Hale Jr., M. E. 1983. The Biology of Lichens 3ed. London: Edward Arnold Publ. 
Huovinen, K. \& Ahti, T. 1986. The composition and contents of aromatic lichen substances in the genus Cladina. Ann. Bot. Fenn., 23:93-106.

Kaighn, M. E., Shankar, K., Ohnuki, J., Lechner, F., Jones, W. 1979. Establishment of characterization of human prostatic carcinoma cell line $\left(\mathrm{PC}_{3}\right)$. Investigative Urology 17:16-23.

Hutchinson, D. J., Ittensohn, O. L., Bjerre-Gaad, M. R. 1966 Growth of L1210 mouse leukemia cells in vitro. Exp. Cell Res. 42:157-170.

Lawrey, M. 1977. Inhibition of moss spore germination by aceton extracts of terricolous Cladonia species. Bull. Torrey Bot. Club. 104(1):49-52.

Legaz, M. E., Vicente, C., Gallo, M., Xavier-Filho, L. 1987. Liçhen phenols from Cladonia dendroides thalli. Lichen Plyysiol. Biochem. 2:13-21.

Lima, R. C., Nascimento, S. C., Pereira, E. C., Campos-Takaki, G. M. 1990. Atividade citotóxica e antitumoral de extratos liquênicos. Bol. Soc. Brot. 63:339-348.

Moore, G. E., Sanberg, A. A., Ulrich, H. 1966. Suspension cell culture and in vivo and in vitro chromosome constitution of mouse leukemia L1210. J. Nat. Cancer Inst. 36:405-421.

Pereira, E. C. G. 1989. Influência da sazonalidade na deteç̧ão de atividade antimicrobiana de Cladonia e Cladina (líquen). Dissertação de mestrado.

Pereira, E. C., Campos-Takaki, G. M., Silva, N. H., Vicente, C., Legaz, M.E., Xavier-Filho, L. 1991. Fractionation of Cladonia substellata crude extracts and detection of antimicrobial activity. Bol. Soc. Brot. 64:173-186.

Pereira, E. C. Nascimento, S.C., Lima, R. C., Silva, N. H., Oliveira, A. F. M., Bandeira, E., Boitard, M., Beriel, H., Vicente, C., Legaz, M. E. (no prelo) Analysis of Usnea fasciata crude extracts with antineoplasic activity. The Tokai Journal of Experimental and Clinical Medicine.

Ravinskaya, A. P. \& Vainstein, E. A. 1975. Effect of some ecological factors on the content of lichen substances. Ekologia 6(3):82-85.

Xavier-Filho, L., Paulo, M. Q., Vicente, C. Legaz, M. E. (1985) Phenols from Cladonia sandstedei analyzed by HPLC. Cryptogam. Bryol. Lichenol. 6(2):143-150. 